\title{
Memoriais na Educação de Jovens e Adultos: vidas, histórias, escritas reflexivas e autobiográficas
}

Rafael Arenhaldt ${ }^{*}$

Juçara Benvenuti**

\begin{abstract}
Resumo:
Este trabalho apresenta e reflete sobre uma experiência didático-pedagógica de escrita de memoriais formativos com sujeitos da Educação de Jovens e Adultos (EJA) em uma escola pública de Porto Alegre. Buscamos, neste ensaio reflexivo, contextualizar esta experiência significativa empreendida com os estudantes da EJA do ensino fundamental, bem como visibilizar o dispositivo da escrita de memoriais como uma estratégia educativa potente nas trajetórias de vida. Em outras palavras, cabe aqui problematizar, enquanto disposição investigativa, de que modo os movimentos reflexivos são manifestos no processo de escrita autobiográfica. Ao relatar o trabalho desenvolvido em aulas do componente curricular Projeto de Investigação (PI), apresentamos os marcadores explicitados e evidenciados no processo de escrita deste público. Os encontros permitiram a preparação, o acompanhamento da construção e a própria produção do memorial.
\end{abstract}

\section{Palavras-chave:}

Memorial. Escrita autobiográfica. EJA.

\begin{abstract}
:
This paper presents and reflects about a didactic-pedagogical experience of writing formative memorials with subjects of youth and adult education (EJA) in a public school in Porto Alegre. In this reflective essay, we intent to contextualize a significant experience undertaken with the EJA' students of elementary school, as well as to make the device of writing memorials like as a powerful and affirmative educational strategy in their life trajectories. In other words, it is here to question, as an investigative disposition, how reflective movements are manifested in the process of autobiographical writing. When reporting the work developed in a Projeto de Investigação (PI) classes, we present the markers made explicited and evidenced in the writing process of this public. The meetings allowed the preparation, monitoring of construction and the production of the memorial itself.
\end{abstract}

\section{Keywords:}

Memorial. Autobiographical writing. EJA.

\footnotetext{
* Professor da área da EJA do Departamento de Estudos Especializados da Faculdade de Educação e professor permanente do Programa de Pós-Graduação em Ensino na Saúde da Faculdade de Medicina da UFRGS. E-mail: rafael.arenhaldt@ufrgs.br. ORCID iD: 0000-0002-0424-1990.

*** Professora de Língua Portuguesa e Literatura do Departamento de Comunicação do Colégio de Aplicação da UFRGS. E-mail: benvenuti@ufrgs.br. ORCID iD: 0000-0003-0243-0373.
} 


\section{Contextualização da proposta: das intenções, disposições e questões mobilizadoras}

“Todo conhecimento é autoconhecimento" (SANTOS, 2008, p. 80).

Este ensaio objetiva entrelaçar as trajetórias inscritas e escritas nos memoriais formativos dos sujeitos da EJA, desde a perspectiva do trabalho. Outrossim, ao nos debruçarmos numa leitura dos textos autobiográficos produzidos pelos estudantes da modalidade EJA, procuramos apresentar algumas reflexões suscitadas das narrativas e das trajetórias individuais e coletivas, procurando entrecruzar suas histórias de vida, as marcas e o modo como essas histórias são contadas.

Cabe destacar que entendemos o memorial formativo enquanto um artefato reflexivo da vida e da formação dos a(u)tores da EJA, enquanto proposta curricular e prática pedagógica com foco na escrita autobiográfica. Nesse sentido podemos problematizar sobre as razões e motivações, sobre os sentidos e a implicação da escrita de memoriais num itinerário formativo para jovens e adultos trabalhadores, numa abordagem interdisciplinar e integradora. Além disso perguntamos: por que desenvolver uma estratégia didática e pedagógica de escrita de memoriais junto a uma turma da modalidade de EJA? Implica questionar, também, se existe sentido formativo e pedagógico em narrar e registrar de forma escrita a própria história de vida?

Começamos evidenciando que o papel da escola na formação e capacitação dos educandos perpassa basicamente a leitura, a escrita e a interpretação. Destacamos que toda atividade de leitura deve engajar-se na preocupação com o processo de letramento dos alunos. Assim, devemos partir dos conhecimentos do mundo a que pertencem os alunos para conseguir alcançar êxito nas atividades propostas (BENVENUTI, 2012). Propor a construção de um texto que parte das suas próprias histórias de vida é permitir que aflore aquilo que é mais conhecido para os alunos, aquilo que eles têm de mais conhecido, os seus domínios de conhecimentos.

Deste modo, a proposta inicial de construção do memorial formativo partiu da identificação do mundo conhecido pelo aluno, trazendo-lhe segurança, confiança. Os passos seguintes do processo de escrita foram gradativamente conduzindo os alunos a novos caminhos até finalmente a produção da escrita autobiográfica. Como isto ocorreu? A seguir há uma descrição detalhada.

\section{Uma proposta didático-pedagógica: do cenário e da configuração}

Essa experiência didático-pedagógica e reflexiva foi efetivada junto a uma turma de estudantes da etapa final do ensino fundamental da modalidade EJA de uma escola pública de Porto Alegre. Neste cenário em que os autores deste ensaio eram os docentes responsáveis pelo Projeto de Investigação (PI) ${ }^{1}$, cabe destacar que ele é um dos componentes curriculares que integra o projeto da EJA da escola.

A turma se caracterizava por se constituir de alunos, que ao mesmo tempo eram servidores da instituição, que interromperam o sonho de ocupar os bancos escolares e concluir a educação básica, e estiveram afastados, por um longo período, dos processos de escolarização. A concretização desse sonho tornou-se possível a partir de uma parceria entre a Escola e o Setor de Desenvolvimento de Pessoal da instituição, evidenciando a importância de conjugar esforços institucionais na implementação de propostas e ações políticas para a elevação da escolaridade ${ }^{2}$.

Construímos uma proposta curricular adequada ao grupo de educandos, incluindo alternativas e estratégias didático-metodológicas que contemplavam uma prática colaborativa e cooperativa, envolvendo todos os atores no processo de aprendizagem. Nessa perspectiva, delinearam-se alguns dos princípios que 
orientaram a prática pedagógica: o respeito aos saberes e aos ritmos de aprendizagem; a valorização das experiências de vida e profissionais; o desenvolvimento de ações interdisciplinares; o estímulo à curiosidade e à prática reflexiva e investigativa. Um dos dispositivos metodológicos utilizados no componente curricular Projeto de Investigação foi a escrita do memorial formativo individual.

Ao longo de um semestre letivo foram desenvolvidas diversas ações e atividades que objetivaram desencadear um processo de reflexão desse grupo de jovens e adultos sobre a sua própria trajetória e história de vida. Assim, cada um dos educandos se aventurou a escrever sobre si em um memorial formativo e elaborou de forma escrita e sistematizada a sua caminhada, ressignificou e produziu outro modo de olhar para as suas experiências de vida, fossem elas pessoais, familiares, escolares, profissionais, culturais, sociais, políticas e/ou comunitárias. Em outras palavras, escreveu um memorial formativo como um modo de assumir a autoria da própria história. Isto é, uma escrita autobiográfica em que a produção de memoriais significou a construção de outro modo de "aprender a dizer a sua palavra" (FIORI, 1987, p. 13) e de reconfigurar os modos de representação de si mesmo, de se recriar e de se reinventar.

\section{Memoriais formativos: do diálogo com os referenciais}

“[...] é contando as nossas próprias histórias que damos a nós mesmos uma identidade. Reconhecemo-nos nas histórias que contamos sobre nós mesmos" (RICOEUR, 1997, p. 426).

A questão que se coloca é: qual o sentido da escrita de memorial num percurso formativo com sujeitos jovens e adultos? Porque despender tamanho esforço numa narrativa pessoal e singular? Existe alguma razão formativa em escrever sobre sua própria trajetória de vida? Em nossa particular compreensão, a resposta à questão acima é afirmativa. Ademais, entendemos que qualquer percurso formativo torna-se mais significativo quando implicado com a própria vida e sua trajetória, suas práticas e experiências. Nosso entendimento é de que a formação se realiza de forma mais efetiva através do conhecimento de si, da reflexão sobre a prática social, na qual o sujeito se encontra envolvido.

Bolívar (2002, p. 69) relata que um percurso formativo para ser significativo, "requer que cada adulto compreenda, se aproprie de sua própria formação e a reconstrua a partir de sua história de vida". Deste modo, partimos do pressuposto de que a narrativa da própria trajetória de vida, através da escrita de memoriais, é formativa e provoca no seu autor um processo de reflexão e autorreflexão, ou seja, a instalação de uma cultura reflexiva no âmbito dos processos de formação. Ao escrever o memorial formativo e ao elaborar em forma de texto sua história, o autor revê e produz uma retrospectiva de suas próprias experiências e vivências - sejam elas pessoais, familiares, escolares, profissionais, comunitárias, culturais, sociais, políticas, espirituais - e, sobretudo, reconfigura os modos de representação de si mesmo e de suas práticas (ARENHALDT, 2012).

Assim, a escrita de memoriais se constitui em um dispositivo valioso, no sentido de produzir compreensões sobre o modo pelo qual nos tornamos as pessoas que somos e a pensar para além daquilo que somos ou dizemos ser. Escrever memorial formativo é

[...] simbolizar a vida na forma de texto, é um exercício de criação, de invenção e reinvenção, que oferece as bases para a sustentação da vida no modo pelo qual decidimos existir. Um exercício de autoconhecimento, de autoprodução da vida, do descobrir-se na condição de pessoa [aprendente]. (ARENHALDT; MARQUES, 2010, p. 19-20).

Escrever um memorial formativo é um modo de assumir a autoria de sua própria história e de assumir-se autor de si. Escrever um memorial formativo é dar forma à sua caminhada de vida. Assim, dizer a sua palavra é também um ato político, é mostrar-se, é assumir-se como agente do/no mundo, é um ato per-formativo, no qual "dizer" é "ser". 
Ser autor é dizer a sua própria palavra, compreender o seu mundo, fazer e escrever sua própria história. Trata-se de um movimento que produz um conhecimento alicerçado na vida, na experiência, que é em si singular, mas produzido na relação com o outro, com o mundo [...]. Escrever um memorial é permitir-se reconhecer e transformar o modo como nos fizemos ser o que somos. Escrever um memorial é ressentir os afetos, sentidos e significados de ser e estar [aprendente]. [...] Escrever um memorial é um movimento de incitar a recriar e reinventar a si mesmo permanentemente. (ARENHALDT; MARQUES, 2010, p. 20).

Contamos e escrevemos nossas histórias como um modo de recriação de nós mesmos. De certa forma, ao contarmos e escrevermos nossa trajetória temos a expectativa de que os outros, ao escutá-la ou lê-la, possam pensar na sua própria existência e no seu modo de vida, na forma que ela está sendo composta e no jeito que ela está sendo produzida e construída. De outra ordem, também somos tomados e invadidos pelas histórias alheias, isto é, as narrativas que lemos e escutamos nos reportam invariavelmente às nossas singulares histórias e às nossas vivências particulares. Se, como afirma Ricoeur (1997, p. 426), "reconhecemo-nos nas histórias que contamos sobre nós mesmos", também nos reconhecemos nas histórias contadas pelos outros e nos formamos ao ler e a escutar o outro. Tal como afirma Benjamin (1994), entende-se que a vida não pode ser separada do modo pelo qual podemos nos dar conta de nós mesmos: narrar nossas histórias é, portanto, um modo de dar a nós mesmos uma identidade. E assim, reinventarmo-nos permanentemente.

Portanto, o memorial formativo é um exercício de autoconhecimento e também de redescoberta do prazer em aprender com. Nessa perspectiva, a escrita de si é resultado do processo reflexivo acerca da vida e da formação. Além disso, empreender a escrita de um memorial formativo, por meio do qual temos a possibilidade de sistematizar e refazer um caminho singular de nossa vida, pode se configurar num outro modo de vislumbrar e avistar novos desfechos e novos desenlaces para a vida que está acontecendo e projetar uma direção ao que ainda pretendemos construir e experimentar como aprendentes (NOGUEIRA et al., 2008).

\section{O resultado final: do processo e da escrita do memorial para um livro ${ }^{3}$}

A organização dos vinte memoriais formativos resultou na composição de um livro digital, onde pode ser percebido o conjunto de estratégias, recursos e atividades desenvolvidas com os sujeitos jovens e adultos em sala de aula e fora dela. Durante o semestre foram realizadas dinâmicas de sensibilização para a produção textual, momentos de leituras de autobiografias e memoriais, com discussões sobre cada um desses gêneros. Além disso, nossa metodologia incluiu oficinas de escrita individual e coletiva, reescrita e revisão das produções, escolhas de títulos e subtítulos, pesquisas em acervo bibliográfico e sites, bem como a organização, seleção e classificação de fotografias do acervo pessoal dos autores, além da configuração de um projeto gráfico do livro digital e sua respectiva capa.

Os testemunhos presentes nos memoriais formativos mostram a trajetória de vida de pessoas que "revelam formas e sentidos múltiplos de existencialidade singular-plural" (JOSSO, 2007, p. 413). Pessoas com as quais construímos cotidianamente uma proposta curricular e metodológica de ensino adequada à sua realidade e às suas necessidades. Para produzir cada texto do memorial, foram necessários empenho e dedicação dos educandos, bem como apoio de uma equipe de bolsistas e colegas docentes e técnico-administrativos.

Um trabalho desse gênero reverencia e referencia a vida de educandos jovens e adultos, mostrando, acima de tudo, o esforço individual na construção de uma sociedade mais preparada para os desafios dos novos tempos. Com o presente material, concede-se a voz e a palavra a esses sujeitos jovens e adultos e busca-se repercutir suas histórias nas instituições de ensino e nos diversos espaços sociais. Trata-se, portanto, de uma obra que possibilita e oportuniza conhecermos um pouco mais das vidas e das histórias dos sujeitos atores e autores da Educação de Jovens e Adultos.

3. O livro intitulado Memoriais: os a(u)tores da educação de jovens e adultos, suas histórias, suas vidas, organizado pelos autores deste artigo, foi encaminhado para publicação em formato digital. 


\section{Marcadores entrecruzados e en(tre)laçados: das escritas autobiográficas}

Apresentamos a seguir algumas das reflexões que a (re)leitura dos memoriais presentes no referido livro suscitou e produziu. Procuramos entrelaçar aspectos marcantes e significativos presentes nas narrativas escritas dos memoriais, dizendo respeito, sobretudo, a perspectiva do trabalho.

A noção de trabalho perpassa e tem centralidade em todos os memoriais, sendo ele o principal elo, já que todos os alunos são colegas servidores da instituição. O trabalho, na perspectiva de Frigotto (2010), é compreendido em sua dupla face: da destruição e da criação da vida. No âmbito da exploração e sua face destrutiva da vida é possível visualizar nos memoriais a presença marcante de episódios e experiências de violação de direitos, situações de trabalho infanto-juvenil, mutilações físicas e psicológicas, da negação de vivências sociais e escolares; o afastamento da escola, a interrupção e a descontinuidade das oportunidades de escolarização, de viver a infância e ser criança, em virtude da necessidade de ajudar a sustentar a casa ou do trabalho da roça. A face da destruição da vida é expressa e manifesta também pelas exigências e contingências de trabalho que impõem restrições às vidas destes sujeitos.

De outra ordem, o trabalho em sua face criadora da vida humana tem como dimensão o "trabalho como princípio educativo", ou seja, o modo pelo qual os sujeitos produzem a sua própria existência, na medida em que se formam através do trabalho, ao mesmo tempo em que o trabalho sustenta a vida. O trabalho nesta perspectiva é compreendido como organizador da vida, criando as condições de possibilidade para as oportunidades formativas. Os testemunhos dos estudantes revelam a valorização e o reconhecimento do trabalho na universidade, sendo que para muitos esta é a principal e mais longínqua experiência de trabalho experimentada, embora a maioria tenha tido uma ou mais experiências de trabalho anteriores ao serviço público, seja no meio rural, no exército ou ainda em serviços diversos.

[...] um belo dia a mesma pessoa que me arrumou este serviço me convidou para trabalhar [na instituição]. Foi aí que tudo começou e minha vida, então, ganhou um melhor sentido em tudo aquilo que eu faço. (Memorial - Estudante 1 - EJA).

Além disso, fica evidente em diversos memoriais que, para muitos, o fato de poder, no seu local de trabalho, viabilizar o sustento financeiro e ainda ter a possibilidade estudar é fator central para a satisfação profissional. Os relatos escritos mostram que o apoio familiar para o retorno à escola e o incentivo institucional para a permanência são essenciais, bem como a valorização no sentido da conclusão do percurso escolar como fundante, já que de outra forma, tudo indica, não teriam as condições ou possibilidade de retomar os estudos (ROLLA, 2014).

[...] enfrento problemas inerentes ao trabalho, mas também muitas coisas boas. Uma delas é hoje poder voltar a estudar com colegas e terminar o Ensino Fundamental, para após seguir adiante no Ensino Médio. (Memorial - Estudante 2 - EJA).

[...] estou muito feliz por ter a oportunidade de concluir meus estudos no Colégio, no Projeto EJA. (Memorial - Estudante 2 - EJA).

[...] voltei a estudar depois de trinta e cinco anos. Alguém falou para mim que abriria vaga no Colégio para fazer o final do Ensino Fundamental. Eu fiz a inscrição. Começaram as aulas. Meus colegas trabalham [na instituição] como eu. (Memorial - Estudante 3 - EJA).

As narrativas que se entrecruzam e se en(tre)laçam nos memoriais formativos dos estudantes da EJA evidenciam a face criadora do trabalho, conforme demonstrou Rolla (2014), que acompanhou os trabalhos desenvolvidos com educandos da EJA. Trata-se de uma experiência coletiva e colaborativa que possibilitou análises minuciosas e apontou olhares diversos sob o processo de escrita autobiográfica e reflexiva.

Salientamos ainda que a dupla face do trabalho apontada por Frigotto (2010), como princípio educativo e como responsável por sustentar a vida, produzem além da organização e sustento, as dimensões subje- 
tivas do reconhecimento, da valorização, da dignidade e do respeito ao ser humano. Fazemos referência à assunção do caráter educativo do trabalho que possibilita, cria e viabiliza tempos e espaços de formação ao longo da vida. Segundo Rolla (2014, p. 40) é "importante lembrar que ao se incorporar a questão do trabalho na formação dos alunos, contribui-se para a construção de novos sentidos e de uma nova força motivadora nos processos formativos".

\section{Buscando 0 arremate: das considerações finais}

Para concluir é preciso retomar as ideias iniciais apresentadas de que este trabalho se desenvolveu no componente curricular chamado Projeto de Investigação (PI) articulando, de forma interdisciplinar, outros docentes e outros componentes curriculares como Língua Portuguesa, Literatura, Letramento Literário, Ciências Humanas e Informática, impactando de forma significativa o trabalho pedagógico e a tecitura curricular da modalidade EJA no colégio.

A produção de um memorial formativo na Educação de Jovens e Adultos de nível fundamental exigiu dos docentes envolvidos adaptação de estratégias, de recursos, de pessoal para alcançar os objetivos propostos. A articulação dos componentes curriculares, o suporte de bolsistas e estudantes da graduação nas questões ligadas ao uso das tecnologias de informação e comunicação, o trabalho em pequenos grupos e de apoio entre colegas e a viabilização de horário extra/alternativo para atendimento aos estudantes, se constituíram em estratégias fundamentais para o desenvolvimento da proposta.

Outrossim, o caminho para a construção do memorial foi composto por muitos passos. Dentre eles: leitura de textos biográficos, autobiográficos, memoriais, discussão e debates para saber a diferença entre os diferentes gêneros, aquisição de conhecimento sobre navegação e pesquisa na internet, escrita e reescrita de textos autobiográficos, pesquisa e entrevistas familiares, busca de informações, recolha de fotografias, seleção de fotografias e de textos, escrita de títulos, leitura em grupo para apreciação entre colegas. O resultado foi a construção de memoriais individuais que foram reunidos em um livro.

Assim, podemos dizer que o resultado do trabalho desenvolvido, expresso na versão finalizada dos textos dos memoriais, mostra que a referida estratégia didático-pedagógica alcançou sucesso, satisfazendo o corpo docente e discente. Mostrou-se como uma atividade significativa, prospectiva, afirmativa e, sobretudo, potente.

A proposta desencadeada junto a alunos da modalidade de Educação de Jovens e Adultos de uma escola pública demonstra que um planejamento pensado a partir da visão de mundo dos educandos, direcionado aos interesses dos alunos e buscando o seu crescimento, a partir dos saberes que eles já trazem ao chegar à escola tende a ser exitosa, independente do tempo para seu desenvolvimento, no nosso caso: um semestre letivo.

Podemos dizer que os jovens e adultos que participaram desta proposta, carregados de experiência de vida, tiveram a oportunidade, através do memorial formativo, de sistematizar e registrar suas vivências e suas histórias. Eles não só escreveram, mas também valorizaram e deram estatuto para o "saber de experiência feito" (FREIRE, 1992, p. 25), para sua trajetória de vida e para os acontecimentos cotidianos. Em resumo, isto é reverenciar, valorizar as pessoas, os episódios que as marcam e as fazem cidadãs do mundo.

\section{Referências}

ARENHALDT, Rafael; MARQUES, Tania Beatriz Iwaszko (org.). Memórias e afetos na formação de professores. Pelotas: Editora da UFPEL, 2010. (Série Cadernos Proeja - Especialização - Rio Grande do Sul, v. I).

ARENHALDT, Rafael. Memorial formativo: a escrita das trajetórias de vida de estudantes de origem popular. In: PEREIRA, Thiago Ingrassia (org.). Há uma Universidade no meio do caminho: caminhadas dos bolsistas do PET/ conexões de saberes da UFFS/Erechim até a universidade. Erechim: Evangraf, 2012. p. 135-147. 
BENJAMIN, Walter. O narrador: considerações sobre a obra de Nikolai Leskov. In: BENJAMIN, Walter. Magia e técnica, arte e política: ensaios sobre literatura e história da cultura. São Paulo: Brasiliense, 1994. p. 197-221.

BENVENUTI, Juçara. O dueto leitura e leitura na educação de jovens e adultos. Porto Alegre: Mediação, 2012.

BOLÍVAR, Antonio. Profissão professor: o itinerário profissional e a construção da escola. Bauru: EDUSC, 2002.

FIORI, Ernani Maria. Aprender a dizer sua palavra (prefácio). In: FREIRE, Paulo. Pedagogia do oprimido. Rio de Janeiro: Paz e Terra, 1987. p. 9-21.

FREIRE, Paulo. Pedagogia da esperança: um reencontro com a pedagogia do oprimido. Rio de Janeiro: Paz e Terra, 1992.

FRIGOTTO, Gaudêncio. A dupla face do trabalho: criação e destruição da vida. In: FRIGOTTO, Gaudêncio; CIAVATTA, Maria (org.). A experiência do trabalho e a educação básica. 3. ed. Rio de Janeiro: Lamparina, 2010. p. 11-27.

JOSSO, Marie-Christine. A transformação de si a partir da narração de histórias de vida. Educação, Porto Alegre, ano XXX, v. 63, n. 3, p. 413-438, set./dez. 2007.

NOGUEIRA, Eliane Greice Davanço et al. A escrita de memoriais a favor da pesquisa e da formação. In: SOUZA, Elizeu Clementino; MIGNOT, Ana Chrystina Venâncio (org.). Histórias de vida e formação de professores. Rio de Janeiro: Quartet/FAPERJ, 2008. p. 169-196.

RICOEUR, Paul. Tempo e Narrativa. Campinas: Papirus, 1997. v. 3.

ROLLA, Stephanie Ma. Trajetórias de trabalho nos memoriais formativos dos alunos da EJA do Colégio de Aplicação. 2014. Trabalho de Conclusão de Curso (Licenciatura em Pedagogia) - Universidade Federal do Rio Grande do Sul, Porto Alegre, 2014.

SANTOS, Boaventura de Sousa. Um discurso sobre as ciências. 5. ed. São Paulo: Cortez, 2008.

Data de submissão: 20/06/2020

Data de aceite: 20/07/2020 